\title{
Uma Rede Discursiva da Educação Ambiental e as Provocações Foucaultianas sobre o Poder Ubuesco
}

\author{
A Discursive Network of Environmental Education and the \\ Foucaultian Provocations about the Ubuesque Power
}

\author{
Isabel Cristina Dalmoro' \\ Suelen Assunção Santos ${ }^{1}$ \\ 'Universidade Federal do Rio Grande do Sul (UFRGS), Instituto de Ciências Básicas da Saúde, \\ Porto Alegre, RS, Brasil. Autora Correspondente: isabel.dalmoro@ufrgs.br
}

\begin{abstract}
Resumo: O presente artigo é recorte da escrita de um estudo que tem por objetivo examinar como o conceito de poder ubuesco, mencionado por Michel Foucault na obra Os Anormais pode servir para lançar outros olhares sobre a Educação Ambiental. O poder ubuesco integra o discurso que tem a uma só vez três propriedades: poder de vida e de morte, poder de verdade e poder de fazer rir. Nessa escrita tencionamos apresentar de que modo o referido conceito pode produzir efeitos na rede discursiva da Educação Ambiental, tendo como base o método da Cartografia. Para tanto, descrevemos alguns elementos que permitem considerar a existência de uma rede discursiva para esse tipo de educação. Além disso, comentamos sobre as três propriedades que compõem o referido discurso que possibilitam pensar o poder ubuesco como um elemento que perpassa a rede discursiva da Educação Ambiental.
\end{abstract}

Palavras-chave: Educação ambiental; Poder ubuesco; Michel Foucault.

Abstract: The present paper is part of a written report on a study which aims to examine how the concept of Ubuesque power, mentioned by Michel Foucault in his work Abnormal, may be used to cast fresh glances over Environmental Education. Ubuesque power integrates a discourse that contains - at the same time - three properties: the power of life and death, the power of truth, and the power of making someone laugh. In this paper we present how that concept may produce effects on the discursive network of Environmental Education, based on cartography. Thus, we describe some elements that allow for the consideration of the existence of one discursive network for Environmental Education. In addition, we comment on the three properties of that discourse that allow for thinking about Ubuesque power as an element that runs through the discursive network of Environmental Education.

Keywords: Environmental education; Ubuesque power; Michel Foucault.

Recebido em: 18/02/2020

Aprovado em: 04/09/2020 


\section{Introdução}

Este texto integra um estudo vinculado à linha de pesquisa que investiga implicações das práticas científicas na constituição dos sujeitos, tendo como base autores que adotam a vertente pós-estruturalista. Trata-se de uma pesquisa que tem por objetivo examinar como o conceito de poder ubuesco, mencionado por Michel Foucault (FOUCAULT, 2010) nas aulas que integram a obra Os Anormais (1974-1975), pode servir para lançar outros olhares sobre a Educação Ambiental. O estudo está baseado no método da Cartografia, pelo qual se busca investigar a produção dessa ferramenta analítica foucaultiana. Em linhas gerais, a Cartografia visa acompanhar um processo de produção de um objeto e não o representar, conforme Kastrup (2015). Assim, acompanhando o processo de produção do poder ubuesco, estamos compondo um novo território para o referido conceito, buscando referenciais teóricos que um cartógrafo pode lançar mão:

[...] pouco importam as referências teóricas do cartógrafo. O que importa é que, para ele, teoria é sempre Cartografia - e, sendo assim ela se faz justamente com as paisagens cuja formação ele acompanha [...]. Para isso, o cartógrafo absorve matérias de qualquer procedência. Não tem o menor racismo de frequência, linguagem ou estilo (ROLNIK, 2011, p. 65).

Desse modo, mapeando sentidos e desdobramentos no processo de sua construção é que se buscou a articulação do poder ubuesco com temas relacionados com a dita crise ambiental vigente e que encontram lugar junto à temática da Educação Ambiental. Nosso propósito é mostrar como o poder ubuesco pode produzir efeitos na rede discursiva desse tipo de educação. Inicialmente, tecemos uma rede discursiva a partir de elementos que possibilitaram pensar numa rede para a Educação Ambiental. Nessa tarefa, puxamos fios oriundos das enunciações proferidas acerca da temática a partir de alguns eventos históricos promovidos para discutir questões pertinentes ao meio ambiente. No fluxo da escrita, comentamos sobre as três propriedades do discurso, o qual, conforme Foucault (2010), se vale do poder ubuesco a fim da maximização dos seus efeitos. As três propriedades contidas nesse discurso são: o poder de vida e de morte, o poder de verdade e o poder de fazer rir. Em seguida, realizamos a operacionalização do referido conceito na malha tecida que possibilitou pensá-lo como um elemento que perpassa a rede discursiva da Educação Ambiental.

\section{Tecendo uma Rede Discursiva da Educação Ambiental}

Rachel Carson (CARSON, 2010) descreveu nos dezessete capítulos de Primavera Silenciosa suas inquietações sobre as consequências da utilização exagerada dos inseticidas sintéticos criados pela Ciência, que agiam sobre as pestilências da natureza (dentre eles, o diclorodifeniltricloroetano - DDT) causando contaminação em rios e lagos, provocando o aparecimento de tumores (em animais e humanos) e a mortandade de peixes, contaminando o solo e as árvores, promovendo a extinção de muitas aves, silenciando a primavera. 
Por conta disso, sugeriu metaforicamente a possibilidade de dois caminhos distintos que consistiam entre a continuação ou não da utilização dos inseticidas sintéticos. Um deles envolvia a estrada "[...] enganosamente fácil, [...] pela qual avançamos em grande velocidade, mas em cujo fim está o desastre" (CARSON, 2010, p. 233). No outro, bem menos percorrido, estava a oferta de alcançar-se, talvez, "a preservação da nossa Terra". Nesse sentido, ao tomar conhecimento desses caminhos, ao fazer a opção por aquele que assegura a preservação da Terra, "[...] não devemos mais aceitar o conselho daqueles que nos dizem que devemos encher o nosso mundo com substâncias químicas venenosas" (CARSON, 2010, p. 233). Desse modo, coube aos seus leitores escolher o caminho a seguir. A alternativa proposta fez com que, semeados pela dúvida, começassem a [se] questionar sobre a Ciência, considerada naquele período histórico como a grande detentora da verdade. São implicações da obra de Carson que interessam para o estudo em andamento. Por ora, um dos efeitos diz respeito ao modo como a Ciência e as indústrias químicas responderam as inquietações de Carson. Respostas essas que tomaram a forma de insultos pessoais contra a autora. Isso porque, para alguns, Carson havia ultrapassado os limites de seu gênero e da sua própria ciência:

Em 1962, contudo, a indústria química multimilionária não iria permitir que uma antiga redatora do governo [Carson trabalhou no Departamento de Pesca], uma cientista sem doutorado [Carson era Mestra em Zoologia] e nenhuma filiação institucional, conhecida apenas por seus livros líricos sobre o mar, minasse a confiança pública em seus produtos ou questionasse sua integridade. Estava claro para a indústria que Rachel Carson era uma mulher histérica cuja visão alarmista do futuro podia ser ignorada ou, caso necessário, silenciada. Ela era uma 'amante dos passarinhos e coelhinhos', uma mulher que tinha gatos e, portanto, era obviamente suspeita. Era uma 'solteirona' romântica, que estava simplesmente nervosa por causa da genética. Em suma, Carson era uma mulher descontrolada (CARSON, 2010, p. 17).

Na listagem dos efeitos promovidos pelo conteúdo de Primavera Silenciosa, talvez o mais relevante deles seja o impulso à mudança na relação entre a espécie humana e o meio ambiente. Relação que passou a ser percebida como uma relação de interdependência entre um e outro, derivando uma nova compreensão do conceito de meio ambiente que se configurou, então, como um problema político de âmbito mundial. Para atender às demandas dessa nova abordagem, foram promovidos encontros com o intuito de discutir diretrizes a serem seguidas numa espécie de pacto global para salvar a Terra. Alinhavando esses encontros, deu-se o entrelaçamento de enunciações que remetem à emergência do discurso da Educação Ambiental.

O primeiro desses encontros aconteceu em Estocolmo, Suécia, em 1972. A Conferência das Nações Unidas sobre o Ambiente Humano foi promovida pela Organização das Nações Unidas (ONU) e, no seu documento final constam, dentre outras, enunciações proferidas reconhecendo a relação mútua entre a espécie humana e o meio ambiente, aproximando-se com o pensamento de Carson. Eis: "[...] os dois aspectos do meio ambiente humano, o natural e o artificial, são essenciais para o bem-estar do homem [...] inclusive o direito à vida mesma" (ORGANIZAÇÃO DAS NAÇÕES UNIDAS, 1972). O documento contém também enunciações sugerindo a necessidade de uma educação voltada para as questões ambientais assumidas como componente das políticas públicas, em vista de um esforço para a preservação e melhoria do meio ambiente. 
Nesse sentido, ocorreu em 1977 na cidade de Tbilisi, Geórgia (ex-URSS), a Primeira Conferência sobre a Educação Ambiental considerada ainda hoje como o marco fundamental desse tipo de educação. Desse encontro despontaram enunciações em torno da Educação Ambiental, com os objetivos, os princípios básicos e as estratégias que orientam este tipo de educação em âmbito regional, nacional e internacional. Dentre as recomendações presentes na Declaração emergida do encontro há a sugestão para que a mencionada educação seja pensada pela perspectiva interdisciplinar de modo a colaborar na compreensão dos problemas ambientais. A adoção de uma perspectiva interdisciplinar para a Educação Ambiental também é uma das enunciações em torno da temática presente na Lei n. 9795 (BRASIL, 1999), lei que integra os discursos legisladores que impulsionaram a referida educação.

Segundo Carvalho (2012), esse caráter interdisciplinar sugerido para a Educação Ambiental pode ser relevante porque, desse modo, busca-se a compreensão das questões que afetam as relações entre a espécie humana e o meio ambiente com a interpelação aos envolvidos a intervir nessas questões pelo impulsionamento de diferentes saberes. Entendemos que esse estudo, pelo qual estamos puxando fios dos campos de saber tanto da Filosofia como da Educação Ambiental, talvez possa fazer parte dos estudos que buscam uma melhor compreensão do recorte da realidade apresentado, tachado sob uma crise ambiental.

No mais, a dita crise ambiental vigente faz parte da trama discursiva que alega que o planeta está passando por um período de mudança climática. Trama discursiva que leva a pensar sobre quais são as condições de possibilidades de se considerar que estamos sob uma crise ambiental? Uma das causas anunciadas para a mudança climática diz respeito ao aquecimento global. Um dos motivos alegados para esse aquecimento recai sobre as atividades humanas ligadas à modernidade. Principalmente sobre aquelas atividades associadas ao aumento da emissão de gases de efeito estufa que poluem a atmosfera. É ainda ligada à modernidade que emerge a Educação Ambiental como um tipo de educação com a tarefa de solucionar problemas ditos ambientais. Leia-se:

[...] Filha da modernidade e herdeira da Educação, ela se consolida na atualidade como solução para os problemas ambientais que vivenciamos. Com discursos de verdade, modos de intervenção para atuarmos no meio ambiente e subjetivações verdes na busca do sonhado equilíbrio ambiental, a Educação Ambiental tenta, desenfreadamente, responder ao que se espera dela. (HENNING; SILVA, 2018, p. 154155).

Outro ponto envolve a discussão sobre o aquecimento global, e a sua possível redução, como mote de um dos mais recentes eventos dentre aqueles mencionados com o intuito de discutir um pacto para salvar a Terra. Trata-se do Acordo de Paris, promovido pela Convenção-Quadro das Nações Unidas sobre Mudança do Clima (UNFCC) no ano de 2015, no qual cento e noventa e cinco países assumiram o compromisso de promover ações a fim de reduzir as ameaças da mudança climática. Ações essas que devem ser voltadas para limitar a elevação da temperatura do planeta abaixo dos dois graus Celsius em relação aos níveis pré-industriais. De acordo com estudo recente, ainda que a meta pretendida seja alcançada, futuramente o mundo ainda estará suscetível de ver aumento nos eventos ocasionados pelo aquecimento global, em comparação com o que ocorre atualmente (DIFFENBAUGH; SINGH; MANKIN, 2018). Por isso, as alegações da 
necessidade de cumprir o Acordo assinado. Das enunciações proferidas no Acordo de Paris há um incitamento às partes para que promovam a educação para a mudança climática. Entendemos que temas como aquecimento global, mudança climática e crise ambiental são importantes para a Educação Ambiental, constituindo-se como integrantes dos discursos que envolvem estratégias pedagógicas da dita educação.

No percurso dos quarenta e um anos do campo do saber da Educação Ambiental, desde a Conferência de Tbilisi, em 1977, até o presente momento, a preocupação com as questões ambientais e as estratégias para a sua abordagem possibilitou a elaboração de uma lista de denominações para a dita educação. Nesse sentido, Sauvé (2005) apresenta quinze maneiras de conceber e praticar a Educação Ambiental para o que se vale da expressão "correntes em Educação Ambiental". Cada uma dessas correntes possui uma abordagem diferente, com discursos e proposições diversas.

Uma das correntes diz respeito à Educação Ambiental da Crítica social, que, inspirada no campo da teoria crítica, tem postura necessariamente política. Isso porque a partir de sua pesquisa emergem projetos de ação sob uma perspectiva emancipatória, em que se promove a "libertação das alienações" (SAUVÉ, 2005, p. 30) e pela qual se busca a desconstrução das realidades socioambientais, desconstrução essa impulsionada pela ação política do indivíduo. Para tentar dar conta da transformação a ela atribuída, ao analisar as dinâmicas sociais baseadas em realidades que apresentam problemáticas ambientais, a Educação Ambiental crítica toma como ferramentas as intenções, as posições, os argumentos e ações dos diferentes protagonistas de uma situação.

No fluxo das pesquisas acerca da Educação Ambiental, Silva e Henning (2018) apresentam um mapeamento realizado em teses, dissertações e artigos científicos que se ocupam com bases epistemológicas, metodológicas e discursivas que compõem a dita educação. Para esse mapeamento, as autoras se valeram das ferramentas conceituais pertinentes à perspectiva filosófica foucaultiana. Por conta da vertente teórica adotada para o estudo, pode ser dito que a mencionada pesquisa se encontra na perspectiva pós-crítica da Educação Ambiental. Perspectiva essa que vai além das correntes da Educação Ambiental relacionadas por Sauvé (2005), caracterizando-se, talvez, como uma nova possibilidade de pensar esse tipo de educação. Possibilidade que se configura como mais um desafio para a Educação Ambiental, somando-se a proposta de pensar a Educação Ambiental pós-crítica tendo como referencial teórico o pensamento foucaultiano. Desafio que encontra justificação pela abordagem adotada por Foucault em seus estudos realizados, já que "[...] refere-se de um autor que cria problemas em um campo que emerge buscando soluções para um problema" (SILVA; GARRÉ, 2018, p. 67). A possibilidade de pensar esse novo campo para a Educação Ambiental encontra apoio na proposta desse estudo, pelo qual estamos buscando um outro olhar para esse tipo de educação imerso no pensamento foucaultiano, pois compreendemos que trazer o pensamento filosófico para atuar junto da Educação Ambiental se mostra como uma alternativa para ajudar a pensar soluções para os problemas atuais (DALMORO, 2019).

Acerca da possibilidade de atravessamentos desses dois modos de pensar a Educação Ambiental, de maneira que essa educação possa sair fortalecida, consideramos relevante dar eco à alegação: 
[...] esses atravessamentos produzem novos atravessamentos e as fronteiras entre uma tradição que se afirma como crítica e uma outra tradição que alguns afirmam como pós-crítica são formadas pelos usos que uns fazem dos outros. Na convivência do debate, novas possibilidades podem ser criadas, experimentadas, tensionadas. O conhecimento e a produção só têm a ganhar (GALLO, 2017 apud SILVA, 2018, p. 114).

Pensando no conjunto variado das pesquisas realizadas em torno da Educação Ambiental que adotaram o referencial filosófico foucaultiano para embasar seus estudos, apresentamos algumas que tratam sobre discursos relacionados às questões ambientais e as suas implicações sobre a constituição dos sujeitos. Nessa perspectiva encontramos estudos que buscam analisar os efeitos dos discursos midiáticos sobre a Educação Ambiental. Conforme Henning, Garré e Henning (2010), o exame desse tipo de discurso pode servir para pensar sobre a influência da mídia - entendida como um mecanismo de poder - em nossos pensamentos e em práticas cotidianas acerca da nossa relação com o planeta. Esse mecanismo de poder presente na sociedade busca capturar e interpelar os sujeitos a tomar ações para preservação da Terra.

Outro estudo envolve a análise sobre a proliferação dos chamados "discursos verdes" no qual as autoras Marques e Henning (2018), buscam problematizar a reprodução e a pulverização desse tipo de discurso, considerados frequentemente como prontos e reducionistas. Tipo de discurso que, segundo as autoras - valendo-se de citação foucaultiana - a sociedade acolhe e faz funcionar como verdadeiros. Nesse sentido, sustentam que "[...] nesses regimes e políticas de verdade, presencia-se uma construção de subjetividade 'verde' ensinando a adotar determinados comportamentos" [...] (MARQUES; HENNING, 2018, p. 426).

Acerca dessa subjetividade verde cabe trazer parte dos estudos realizados por Sampaio e Guimarães (2012), nos quais os autores discorrem sobre o dispositivo da sustentabilidade que atua, numa espécie de linhas de forças, de forma ativa na fabricação dos sujeitos. No caso, na fabricação de sujeitos "verdes". A noção de dispositivo adotada pelos autores é aquela apresentada por Foucault (2006, p. 244), que, resumidamente, diz respeito ao "[...] conjunto decididamente heterogêneo que engloba discursos, instituições, organizações arquitetônicas, decisões regulamentares, leis, medidas administrativas, enunciados científicos, proposições filosóficas, morais, filantrópicas". Assim como se constitui a partir de uma rede entre o visível e o dizível.

Uma vez que se está examinando um discurso que envolve o poder ubuesco presente na obra de Foucault, autor vinculado à vertente pós-estruturalista, e as ressonâncias desse discurso na rede discursiva da Educação Ambiental, entendemos que o presente estudo se amarra a esse modo de olhar para a dita educação, por conta do seu lugar de fala. Na abordagem pós-estruturalista, em linhas gerais, há a ocupação com o discurso e os seus efeitos sobre os sujeitos, como também com o conceito de poder. Outro ponto que caracteriza a perspectiva pós-estruturalista, baseada no pensamento foucaultiano, é o que entende o saber como algo que não é externo ao poder. Desse modo, tomando o campo da Educação Ambiental como um saber, o presente estudo mapeia como o poder ubuesco atua no saber dito ambiental, uma vez que "[...] não existe saber que não seja a expressão de uma vontade de poder. Ao mesmo tempo, não existe poder que não se utilize do saber" (SILVA, 2010, p. 120). 
Isso posto, pensamos uma rede discursiva a partir da perspectiva foucaultiana de discurso, qual seja, "[...] discursos como práticas que formam sistematicamente os objetos dos quais falam" (FOUCAULT, 2008, p. 55). Ou seja, consideramos discurso não somente como um ato de fala ou como a ação de pronunciar discursos, mas relacionamos também com as práticas que moldam nossos modos de ser. Uma porque entendemos que outras redes poderão ser formadas a partir de diferentes perspectivas.

De acordo com Pinheiro (2014), para Foucault (2008), a ideia de discurso passa pela rejeição do referido conceito como uma expressão de fala do sujeito produtor de significados. Nesse sentido, quando há a menção de discurso, é pela referência das práticas que "[...] estabelecem hierarquias, distinções, que configuram as possibilidades de outros discursos serem considerados verdades, articulando o visível e o dizível" (PINHEIRO, 2014, p. 41), que o discurso deve ser compreendido. Desse modo, ao considerarmos os múltiplos elementos formados de maneira regular em torno do meio ambiente e a educação para a sua proteção, tecemos essa rede discursiva da Educação Ambiental.

Ainda, aproveitando que a produção de um discurso nada mais é que uma fabricação e que "[...] inventamos o objeto no mesmo instante que começamos a descrevê-lo" (HENNING; GARRÉ; HENNING, 2010, p. 245), compreendemos a derivação de uma trama discursiva que produziu a Educação Ambiental pelo entrelaçamento dos discursos apresentados ao longo dessa seção. Trama essa que se tornou possível porque puxamos alguns fios que tornaram possível a existência da Educação Ambiental e pelos quais tecemos amarras em torno da temática possibilitando pensar uma rede discursiva para esse tipo de educação. Rede essa que tem como função sustentar o estudo de um discurso que, tal como descreveu Foucault, envolve uma força que faz dizer e faz ver, que interdita ou libera - assim como qualquer poder. Força essa que promove a desqualificação de quem produz o discurso que dela se vale, maximizando os efeitos desse discurso. Efeitos esses que podem ter ressonâncias sobre essa mesma rede. Tratase do poder ubuesco.

\section{O Poder Ubuesco}

O poder ubuesco foi mencionado nas duas primeiras aulas que integram a obra Os Anormais. Inicialmente, Foucault (2010) chamou a atenção para o conteúdo de dois relatórios lidos na primeira aula do curso que remetem a um discurso que possui a uma só vez três propriedades, quais sejam:

[...] são raros, numa sociedade como a nossa, os discursos que possuem a uma só vez três propriedades. A primeira é poder determinar, direta ou indiretamente [...] à liberdade ou à detenção de um homem [...] são discursos que têm, no limite, um poder de vida e de morte. Segunda propriedade: de onde lhes vem esse poder? Da instituição judiciária [...]funcionam [...] como discursos de verdade, discursos de verdade porque discursos com estatuto científico [...] Discursos que podem matar, discursos de verdade e discursos - vocês são prova e testemunha disso - que fazem rir. E os discursos de verdade que fazem rir e que têm o poder institucional de matar são, no fim das contas, numa sociedade como a nossa, discursos que merecem atenção. (FOUCAULT, 2010, p. 6-7). 
Discursos que podem matar, discursos de verdade e discursos que fazem rir.

"Vocês são prova e testemunha disso", o comentário de Foucault (2010, p. 7) exposto na citação acima diz respeito aos risos frequentes que acompanharam a leitura dos relatórios realizada por ele ${ }^{1}$. Risos esses provocados pelas descrições grotescas presentes nos supramencionados relatórios. Descrições como as que Foucault leu de um dos relatórios que envolvia chantagem num caso sexual, do qual apresentamos passagens:

[...] X é totalmente imoral, cínico, falastrão até. [...] Só vendo o ar afeminado de um e de outro para compreender que tal palavra pode ser empregada quando se trata de dois homens tão afeminados que não é mais em Sodoma, mas em Gomorra que deveriam viver [...] (FOUCAULT, 2010, p. 6).

A partir dessas caracterizações, que remetem ao grosseiro e que suscitam, ao mesmo tempo, ironia e crítica, é que Foucault começou a tratar do conceito de poder ubuesco. A crítica foucaultiana recaiu sobre um discurso em que os saberes judiciário e científico se encontraram, adquirindo o estatuto de um discurso verdadeiro, discurso capaz de matar e de fazer rir. Ainda, dele decorre "[...] a maximização dos efeitos de poder a partir da desqualificação de quem os produz" (FOUCAULT, 2010, p. 11). Por causa dessa desqualificação, não há a possibilidade de uma resposta racional ao discurso que lança mão do poder ubuesco. Desse modo, essa categoria do ubuesco não pode ser considerada uma falha mecânica do poder. Ela serve a quem está exercendo o poder, maximizando-o.

Acerca dos discursos de verdade, cabe dizer que, pela perspectiva foucaultiana, a verdade é compreendida sob a expressão "jogos de verdade" e tem a ver com o conjunto de regras de produção da verdade que permitem o sujeito tomar algo como verdadeiro. Isso ocorre porque é a sociedade que estabelece sua política de verdade, com seus mecanismos e instâncias próprias, sendo sempre regras arbitrárias. Nesse sentido, "[...] a verdade não apenas se constitui como um produto histórico, [...] constitui modos de verse, dizer-se e conduzir-se. Elas sedimentam determinados tipos de saberes e excluem outros" (BELLO; SANCHOTENE, 2018, p. 143).

No âmbito desse estudo, citamos como exemplos os discursos da Ciência apresentados anteriormente acerca dos efeitos do uso do DDT - nesse caso, sobre o inseticida não ser nocivo aos seres humanos -, discursos que eram tomados como verdadeiros por boa parte da sociedade daquele período. Assim como as verdades acerca da relação espécie humana e natureza - o equilíbrio da natureza era fundamental para a sobrevivência da espécie -, que motivaram Carson (2010) a escrever Primavera Silenciosa em 1962.

Foucault (2010) descreveu os discursos que podem matar como sendo a situação limite estabelecida de uma decisão de justiça, para além do veredito da liberdade ou da detenção de um indivíduo. Com o propósito de mostrar o funcionamento da verdade judiciária e a emergência dos relatórios periciais nesse campo, relembrou o modo como a instituição judiciária obtinha as provas legais que possibilitavam a condenação ou não de um réu e como a maneira de administrar tais provas na prática penal suscitavam "ao mesmo tempo ironia e crítica" (FOUCAULT, 2010, p. 6-7) constituindo-se como elementos

${ }^{1}$ Conforme a nota 11 da tradução utilizada neste trabalho e citada no parágrafo. 
dos quais os juízes poderiam lançar mão para modular a aplicação da lei. Elementos que eram combinados para chegar a uma certa quantidade de prova, com o intuito de se obter o mínimo necessário para o tribunal tomar a decisão de condenar um indivíduo.

Nesse sentido, Foucault $(2010,2017)$ chamou a atenção para os casos em que crimes eram cometidos aparentemente "sem razão", entendidos como crimes sem interesse, sem paixão, sem motivos. Mas, com base em delírios. Por conta do embaraço desse tipo de situação para o sistema penal, entraram em cena, para servirem também como provas, os relatórios elaborados a partir dos interrogatórios policiais e dos exames psiquiátricos de âmbito penal. Ponto em que se encontraram o tribunal e o cientista, onde cruzaram "[...] a instituição judiciária e o saber médico ou científico em geral" (FOUCAULT, 2010, p. 10-11). Algumas dessas provas teriam em si "efeitos de poder, valores demonstrativos, uns maiores que os outros" (FOUCAULT, 2010), por conta do sujeito que as produz. Um exemplo de situação que passa da condição dada pela justiça que vai além do poder de determinar a liberdade ou a detenção de um indivíduo, ou seja, o poder de vida e morte, envolve a punição da figura do hermafrodita que foi condenado à morte após um exame em que "[...] os médicos concluíram que, de fato, aquele indivíduo possuía os dois sexos, e que só podia possuir os dois sexos porque tivera relações com Satanás" (FOUCAULT, 2010, p. 57).

No caso exposto percebemos a atuação conjunta dos respectivos saberes, adquirindo o estatuto de um discurso verdadeiro, no qual podemos notar o ajuntamento das propriedades que caracterizam o tipo de discurso que abarca o poder ubuesco: poder de vida e de morte, poder de verdade e o poder de fazer rir. Riso oriundo de um humor grotesco.

"Vocês são prova e testemunha disso", conforme já dito, foi o modo como Foucault $(2010$, p. 7) chamou a atenção para um discurso que, segundo ele, faz parte dos discursos da instituição judiciária: discursos que fazem rir. Consoante com a manifestação do riso frequente durante a leitura dos relatórios elaborados pelos peritos psiquiatras em matéria penal, aceitamos que o riso faz parte da experiência humana. Ainda, para Souto, Junges e Fachin (2011), o riso é produto de uma cultura, resultante de uma complexidade social, dado que nem todos riem pelos mesmos motivos e pelas mesmas circunstâncias.

De modo geral, essa proposição tem relação com o que é sustentado por Leme (2018), a saber, para quem lê Foucault, o riso pode ser bem mais que uma manifestação de alegria ou de zombaria e "[...] os leitores de Foucault sabem que o riso não é uma realidade homogênea, nem todos riem das mesmas coisas pelas mesmas razões" (LEME, 2018, p. 181). Por conta disso, chama a atenção para aquelas narrativas aparentemente inofensivas que, com aparência de anedota com intuito de relaxamento merecido, podem ocultar coisas decisivas em jogo. Nesse sentido, sustenta ainda que o principal desafio da análise do poder ubuesco consiste na forma de combatê-lo. Isso porque se trata de um mecanismo que recorre à despolitização e à exasperação que "[...] começam pela autodesqualificação do governante e terminam com o desespero dos governados, seja na forma do riso resignado, seja na forma de desistência" (LEME, 2018, p. 185).

Nessa lógica é que entendemos as provocações de Foucault (2010) acerca dos discursos que fazem rir e que merecem atenção. O tipo de riso que Foucault comentou, a partir das descrições presentes nos relatórios supramencionados, é oriundo de um humor sarcástico, com conteúdo grotesco e que impossibilita pensar em uma resposta racional ao que realmente está em jogo. Um exemplo que pode ser trazido sobre isso 
são as expressões utilizadas pelos peritos psiquiatras nos relatórios lidos por ele em aula, a saber: "[...] X é totalmente imoral, cínico e falastrão até" (FOUCAULT, 2010, p. 6). Expressões que, segundo o autor, são do âmbito das qualificações morais e das regras éticas que não são supostamente alguma coisa contra a lei, mas que acabam possuindo o estatuto de discurso verdadeiro. Desse modo, descreveu uma espécie de força atuante nesse tipo de discurso que maximiza os seus efeitos de poder, a partir da desqualificação de quem os produz. Força essa que é caracterizada como poder ubuesco, ingrediente do discurso do Ubu. Conforme:

[...] Ubu é o exercício do poder através da desqualificação explícita de quem o exerce, se o grotesco político é a anulação do detentor de poder pelo próprio ritual que manifesta esse poder e esse detentor, vocês hão de convir que o perito psiquiatra na verdade não pode deixar de ser o próprio personagem Ubu. (FOUCAULT, 2010, p. 31).

Dada a citação acima, em que o grotesco político de Ubu é mencionado, entendemos como uma menção à personagem da peça da qual o adjetivo ubuesco derivou, qual seja, a peça Ubu-roi² escrita em 1896 por Jarry (1986). Trata-se de uma personagem que demonstra tirania, covardia e que se vale de um tipo de humor irônico. Conforme Jarry (2007, p. 34), "[...] o senhor Ubu é um ser ignóbil, e por isso ele (por baixo), lembra a todos nós". Por conta disso, é que podemos pensar que as falas e as atitudes do Pai Ubu perpassam o tempo e o espaço, pois "[...] Ubu-rei continua sua história de transgressões, ainda que seu protagonista tenha perdido muito do caráter diabólico, graças a competição desleal da cena contemporânea" (FERNANDES, 2007, p. 27). No contexto desse estudo, compreendemos que a personagem Ubu adquiriu uma nova persona e se mostra sob a figura de um "Ubu presidente" (DALMORO, 2019). Todavia, por ora, o objetivo dessa seção foi tratar das três propriedades do discurso que abarca o poder ubuesco e, assim como para Foucault (2010), nos interessa estudar os efeitos de poder desse discurso.

\section{O Poder Ubuesco na Rede Discursiva da Educação Ambiental}

Ao darmos continuidade no exame dos efeitos do poder ubuesco na rede discursiva da Educação Ambiental, adiantamos que as considerações a seguir acerca da Ciência são postas para analisar as três propriedades do discurso que abarcam o poder ubuesco, trazendo a possível relação entre ambos e, desse modo, abordar sobre os seus possíveis efeitos.

Partimos, para tanto, do contexto histórico do período do lançamento da obra de Carson (2010), que pode ser descrito como um tempo em que a Ciência e, por conseguinte, o conhecimento científico, era tomado como verdadeiro por boa parte da população mundial. Por conta do avanço científico, o pensamento da época era o de que a Ciência poderia resolver qualquer problema, num cenário em que se acreditava que a tecnologia daria conta até dos problemas ambientais. No que tange às questões ambientais, atentamos que a Ciência era considerada como detentora do poder de vida e de morte por produzir e defender o uso do DDT, ainda que alguns estudos daquele

\footnotetext{
²Ubu-rei ou Rei Ubu.
} 
período já apontassem para a incidência de tumores tanto na espécie humana como em não-humanos em decorrência do uso do inseticida. Em relação ao poder de fazer rir, retomamos os insultos que a indústria química e a Ciência [por parte de alguns cientistas] dirigiram à autora de Primavera Silenciosa. Entendemos que expressões como: uma alarmista histérica, lésbica amante dos gatos, comunista, solteirona e, uma mulher descontrolada são aproximações que podemos fazer com a propriedade de fazer rir, aproximações essas que talvez possam ser pensadas como vestígios do poder ubuesco na rede discursiva da Educação Ambiental. Isso pode ser dito porque tanto os cientistas como a indústria ao lançarem mão do poder ubuesco, valendo-se do sarcasmo e do grotesco em seus discursos, estariam se desqualificando impossibilitando uma resposta racional às coisas ditas.

Para pensar os efeitos do poder ubuesco na rede discursiva da Educação Ambiental já em tempo mais presente, retomamos os temas do aquecimento global, da mudança climática e do Acordo de Paris. Tanto o aquecimento global como a mudança climática inserem os tempos atuais numa situação planetária considerada sob uma crise ambiental. Nesse contexto, surgiram enunciações que chamaram e mereceram nossa atenção. Enunciações que foram proferidas pelo presidente dos Estados Unidos da América no período 2017-2021, Donald Trump, as quais geraram polêmicas sobre o assunto e que foram trazidas para esse estudo por conta das aproximações com o discurso que abarca o poder ubuesco uma vez que nelas encontramos a tríade: o poder de vida e de morte, o poder de verdade e o poder de fazer rir. Num primeiro momento, devido ao cargo ocupado, Donald Trump teria o poder de vida e de morte, o que é possível de ser exemplificado a partir de seu poder de decisão acerca de iniciar ou não uma guerra. Além disso, por conta do cargo desempenhado, possuiria o poder de verdade, conferido a ele por seus eleitores no ano de 2016.

Acerca da terceira propriedade do discurso que abarca o poder ubuesco, sobreveio o encontro com a temática ambiental. Isso porque Donald Trump divulgou ainda no ano de 2012 em uma de suas redes sociais não acreditar no aquecimento global. 0 que chamou a atenção para esse estudo foram as expressões utilizadas por ele naquele momento. Segundo a mensagem postada, o aquecimento global não passaria de uma mentira inventada pelos chineses com a intenção de prejudicar comercialmente o país que governava. A dita ameaça chinesa, pela qual geraria a estagnação da economia americana, foi utilizada como apelo aos eleitores na condição de candidato ao governo dos EUA. Assim que eleito, uma das medidas postas em ação consistiu na retirada do país norte-americano do Acordo de Paris. No meio de muitas polêmicas acerca de sua decisão, o então presidente novamente se valeu das redes sociais para manifestar-se. $A$ postagem justificava a saída dos EUA do Acordo de Paris com a alegação de que desse modo o país voltaria a crescer economicamente. Além disso, Donald Trump continuou ironizando o aquecimento global. Mais uma vez, em postagem em uma de suas redes sociais, lançou mão da ironia ao escrever que cairia bem o velho e bom aquecimento global para proteger os norte-americanos das baixas temperaturas do período.

São as expressões irônicas utilizadas por Donald Trump que entendemos como passíveis de ser relacionadas com o poder de fazer rir, propriedade do discurso que abarca o poder ubuesco. Dado que tais expressões remetem ao tipo de termos utilizados pelos peritos psiquiatras em matéria penal apresentados nos relatórios lidos por Foucault (2010). Lembram também as falas do personagem Pai Ubu, 
contendo um tipo de humor grotesco. Ainda, as expressões utilizadas por ele se valem do sarcasmo, do grotesco, se quiserem do ubuesco, para tratar de temas pertinentes à temática ambiental, impossibilitando uma resposta racional as suas declarações, pela desqualificação de seu próprio discurso.

Pela operacionalização do conceito de poder ubuesco sobre questões ambientais emergem considerações sobre o papel da Ciência nas relações de força apresentadas. Relembramos que na primeira dessas relações, a Ciência [ao menos parte dela] lançou mão em seus discursos do poder ubuesco para depreciar as provocações apresentadas por Carson (2010) na Primavera Silenciosa, na qual questionou o uso exagerado do DDT tanto em lavouras como em cidades, e que era atestado como um inseticida inofensivo aos humanos pela Ciência daquele período. No segundo exemplo, a Ciência [ao menos parte dela] é a vítima da situação, por conta dos discursos envolvendo o presidente norte-americano e os temas do aquecimento global e da mudança climática. Nos dois exemplos encontramos a presença do poder de fazer rir. Riso irônico. Além disso, a Ciência pode ser considerada como portadora de um discurso que tem poder de vida e de morte, como também de um discurso verdadeiro. No que envolve a temática ambiental, por conta do poder de verdade que lhe é atribuído, outras verdades e muitos acordos de âmbito internacional foram efetivados em seu nome. Dessas verdades se evidenciam como resultantes a adoção de estilos de vida e modos de conduta em torno da nossa relação com os problemas ambientais.

No entanto, a respeito dos exemplos apresentados, emergem inquietações e questionamentos. Dentre outros, elencamos: não caberia pensar com certo estranhamento os saberes da Ciência? Saberes esses que permitiram o uso do grotesco, do ubuesco. Não serviriam tais exemplos para nos provocar, nos incomodar, diante dos saberes ditos legítimos e propagados como verdadeiros? Nessa correnteza, de que modo esses saberes produzem efeitos sobre a Educação Ambiental? Qual Educação Ambiental emerge a partir desses discursos? Afinal, como lidar com os discursos que se valem do poder ubuesco na rede discursiva da Educação Ambiental e dos quais nem rimos mais? (DALMORO, 2019).

No fluxo da perspectiva filosófica foucaultiana, consideramos que não exista um saberque seja neutro. Isso porque os saberes estão de algum modo relacionados às relações de força, relações ligadas às condições políticas (FOUCAULT, 2006). Compreendemos também que a incomodação em relação a Ciência trazida à tona pela operacionalização do poder ubuesco sobre questões ambientais pertinentes à modernidade pode adquirir um sentido positivo, uma vez que por meio desse estranhamento e dessa incomodação um outro modo de olhar o mundo pode emergir. Nesse caso, envolve repensar a Ciência e seus ditos, repensar a temática desse estudo, pois, conforme já exposto, a Educação Ambiental é resultante da modernidade e como tal:

[...] se pauta por verdades tão bem solidificadas em nós que, muitas vezes, esquecemos que são ditos fabricados como legítimos e tomados como necessários para construirmos novas subjetividades em tempos de crise ambiental (HENNING; MUTZ; VIEIRA, 2018, p. 9). 
Parece-nos ainda que, do descrito acerca das inquietações em torno das relações envolvendo a Ciência, tanto merece nossa atenção considerar os efeitos quando essa narra sobre o aquecimento global e a mudança climática derivada dele, quanto também pensar sobre os efeitos da sua atuação quando permeada pela Política e por um discurso que se vale do poder ubuesco. Ademais, cabe pensar sobre os efeitos dessa relação, Ciência, Política e poder ubuesco sobre a temática da Educação Ambiental e a nossa atual relação com o planeta.

\section{Considerações Finais}

Ao longo dessa escrita tecemos uma rede discursiva da Educação Ambiental com o intuito de dar suporte ao estudo do poder ubuesco, como também, colaborar com a operacionalização com o referido conceito, servindo como alvo sobre a qual os seus efeitos podem também efetuar-se. Nesse sentido, entendemos que ao lançar mão do poder ubuesco como força atuante na rede discursiva da Educação Ambiental, força que perpassa seus discursos, a maximização dos seus efeitos de poder tanto pode atingir seres humanos e não-humanos.

Reconhecemos, desse modo, que o discurso que abarca o poder ubuesco se faz presente na rede discursiva da Educação Ambiental, muitas vezes tratada sob esfera irônica no que tange aos seus próprios discursos. Desse modo, pela análise até agora realizada acerca do conceito de poder ubuesco, podemos aferir que se trata de uma força que é capaz de fazer agir e de interditar. Ademais, por conta da abordagem realizada, afirmamos o campo filosófico como um colaborador da compreensão dos tempos atuais, pelo qual foi possível lançar um outro olhar sobre esse tipo de educação.

\section{Referências}

BELLO, S. E. L.; SANCHOTENE, V. C. Pensamento e verdade na educação (matemática): conversações com Foucault e Deleuze. Revista de Educação, Ciência e Cultura, Canoas, v. 23, n. 1, p. 141-147, 2018. Disponível em: https://revistas.unilasalle.edu.br/index.php/Educacao/article/ view/4197. Acesso em: 27 jan. 2020.

BRASIL. Lei 9.795 de 27 de abril de 1999. Dispõe sobre a educação ambiental, institui a Política Nacional de Educação Ambiental e dá outras providências. Brasília, DF: Presidência da República, 1999. Disponível em: http://www.planalto.gov.br/ccivil_03/leis/19795.htm. Acesso em: 27 jan. 2020.

CARSON, R. Primavera silenciosa. São Paulo: Gaia, 2010.

CARVALHO, I. C. M. Educação ambiental e a formação do sujeito ecológico. 6. ed. São Paulo: Cortez, 2012.

DALMORO, I. C. Educação ambiental e o desdobramento do poder ubuesco: uma análise foucaultiana. 2019. Dissertação (Mestrado em Educação em Ciências) - Instituto de Ciências Básicas da Saúde, Universidade Federal do Rio Grande do Sul, Porto Alegre, 2019. Disponível em: https://www.lume.ufrgs.br/handle/10183/193669. Acesso em: 0 fev. 2021.

DIFFENBAUGH N.; SINGH D.; MANKIN, J. S. Unprecedented climate events: historical changes, aspirational targets, and national commitments. Science Advances, Washington, v. 4, n. 2, p. 1-9, 2018. DOI: https://doi.org/10.1126/sciadv.aao3354.

FERNANDES, S. Alfred Jarry. In: JARRY, A. Ubu-Rei. São Paulo: Peixoto Neto, 2007. p. 11-27. 
FOUCAULT, M. A evolução da noção de "indivíduo perigoso" na psiquiatria legal do século XIX. In: FOUCAULT, M. Ditos e escritos V: ética, sexualidade, política. 3. ed. Rio de Janeiro: Forense Universitária, 2017. p. 1-24.

FOUCAULT, M. Os anormais. 2. ed. São Paulo: WMF Martins Fontes, 2010.

FOUCAULT, M. A arqueologia do saber. 7. ed. Rio de Janeiro: Forense Universitária, 2008.

FOUCAULT, M. Microfísica do poder. 22. ed. Rio de Janeiro: Graal, 2006.

HENNING, C. C.; GARRÉ, B. H.; HENNING, P. C. Discursos da educação ambiental na mídia: uma estratégia de controle em operação. Remea: revista eletrônica do mestrado em educação ambiental, Rio Grande, v. 25, p. 243-252, 2010 Disponível em: https://periodicos.furg.br/remea/ article/view/3512. Acesso em: 27 jan. 2020.

HENNING, P. C.; SILVA, G. R. Rastros da educação ambiental: o dissenso como potência criadora. In: HENNING, P. C.; MUTZ, A. S. C; VIEIRA, V. T. (org.). Educações ambientais possíveis: ecos de Michel Foucault para pensar o presente. Curitiba: Appris, 2018. p. 151-162.

HENNING, P. C.; MUTZ, A. S. C.; VIEIRA, V. T. Possíveis ecos de Michel Foucault na educação ambiental. In: HENNING, P. C.; MUTZ, A. S. C; VIEIRA, V. T. (org.). Educações ambientais possíveis: ecos de Michel Foucault para pensar o presente. Curitiba: Appris, 2018. p. 9-16.

JARRY, A. Outra apresentação de Ubu Rei. In: JARRY, A. Ubu-Rei. São Paulo: Peixoto Neto, 2007. p. 33-35.

JARRY, A. Ubu-Rei. São Paulo: Max Limonad, 1986.

KASTRUP, V. O funcionamento da atenção no trabalho do cartógrafo: pista 2. In: PASSOS, E.; KASTRUP, V.; ESCÓSSIA, L. (org.). Pistas do método da cartografia: pesquisa-intervenção e produção de subjetividade. 4. ed. Porto Alegre: Sulina, 2015. p. 32-51.

LEME, J. L. C. A crise da governamentalidade e o poder ubuesco. In: ALBUQUERQUE JR., D. M.; VEIGA-NETO, A.; SOUZA FILHO, A. (org.). Cartografias de Foucault. 2. ed. Belo Horizonte: Autêntica, 2011. p. 181-197.

LEME, J. L. C. O poder ubuesco e o meio riso. In: RESENDE, H. (org.). Michel Foucault: o ronco surdo da batalha. São Paulo: Intermeios; Brasília: Capes, 2018. p. 177-185.

MARQUES, I. R.; HENNING, P. C. Discursos ambientais e a (re) produção de verdades. In: PEREIRA, V. A.; GARCIA, N. M. (coord.). Anais do IX encontro e diálogos com a educação ambiental: educação ambiental como espaço de resistência. Rio Grande: Editora da FURG, 2018. p. 421-429. Disponível em: https://cutt.ly/zkKWvUu. Acesso em: 27 jan. 2020.

ORGANIZAÇÃO DAS NAÇÕES UNIDAS. Declaração da conferência da Organização das Nações Unidas sobre o meio ambiente humano. Estocolmo: ONU, 1972. Disponível em: https://cutt.ly/ zkKWXcm. Acesso em: 27 jan. 2020.

PINHEIRO, J. M. Estudantes forjados nas arcadas do Colégio Militar de Porto Alegre (CMPA): "novos talentos" da Olímpiada Brasileira de Matemática das Escolas Públicas (OBMEP). 2014. 230 f. Tese (Doutorado em Educação) - Universidade do Vale do Rio dos Sinos, São Leopoldo, 2014. Disponível em: http://www.repositorio.jesuita.org.br/handle/UNISINOS/3323. Acesso em: 27 jan. 2020.

ROLNIK, S. Cartografia sentimental: transformações contemporâneas de um desejo. 2. ed. Porto Alegre: Sulina: Editora da UFRGS, 2011.

SAMPAIO, S. M. V.; GUIMARÃES, L. B. O dispositivo da sustentabilidade: pedagogias no contemporâneo. Perspectiva, Florianópolis, v. 30, n. 2, p. 395-409, 2012. DOI: https://doi. org/10.5007/2175-795X.2012v30n2p395. 
SAUVÉ, L. Uma cartografia das correntes em educação ambiental. In: SATO, M.; CARVALHO, I. C. M. (org.). Educação ambiental: pesquisas e desafios. Porto Alegre: Artmed, 2005. p. 17-44.

SILVA, L. S. Educação ambiental e sua produção científica: tensionamentos, relações de força e produção de verdades. 2018. Dissertação (Mestrado em Educação Ambiental) - Universidade Federal do Rio Grande, Rio Grande, 2018.

SILVA, L. S.; GARRÉ, B. H. Michel Foucault na educação ambiental: a produção científica do GT 22 da ANPEd sob análise. In: HENNING, P. C.; MUTZ, A. S. C.; VIEIRA, V. T. (org.). Educações ambientais possíveis: ecos de Michel Foucault para pensar o presente. Curitiba: Appris, 2018.

SILVA, L. S.; HENNING, P. C. A educação ambiental e a sua produção científica: um olhar para as diferenças. Perspectiva, Florianópolis, v. 36, n. 3, p. 978-991, 2018. DOI: https://doi. org/10.5007/2175-795X.2018v36n3p978.

SILVA, T. T. Documentos de identidade: uma introdução às teorias do currículo. Belo Horizonte: Autêntica, 2010.

SOUTO, M. G. F.; JUNGES, M.; FACHIN, P. O riso e suas interdições na sociedade. IHU on-line: revista do Instituto Humanitas Unisinos, n. 367, p. 21-23, 2011. Disponível em: http://www.ihuonline. unisinos.br/media/pdf/IHUOnlineEdicao367.pdf. Acesso em: 9 fev. 2021. 